\title{
Ticagrelor: Pharmacokinetic, Pharmacodynamic and Pharmacogenetic Profile: An Update
}

\author{
Renli Teng ${ }^{1}$
}

Published online: 11 June 2015

(c) The Author(s) 2015. This article is published with open access at Springerlink.com

\begin{abstract}
Despite advancements in treatments for acute coronary syndromes over the last 10 years, they continue to be life-threatening disorders. Currently, the standard of treatment includes dual antiplatelet therapy consisting of aspirin plus a $\mathrm{P} 2 \mathrm{Y}_{12}$ receptor antagonist. The thienopyridine class of $\mathrm{P} 2 \mathrm{Y}_{12}$ receptor antagonists, clopidogrel and prasugrel, have demonstrated efficacy. However, their use is associated with several limitations, including the need for metabolic activation and irreversible $\mathrm{P}_{2} \mathrm{Y}_{12}$ receptor binding causing prolonged recovery of platelet function. In addition, response to clopidogrel is variable and efficacy is reduced in patients with certain genotypes. Although prasugrel is a more consistent inhibitor of platelet aggregation than clopidogrel, it is associated with an increased risk of life-threatening and fatal bleeding. Ticagrelor is an oral antiplatelet agent of the cyclopentyltriazolopyrimidine class and also acts through the $\mathrm{P}_{2} \mathrm{Y}_{12}$ receptor. In contrast to clopidogrel and prasugrel, ticagrelor does not require metabolic activation and binds rapidly and reversibly to the $\mathrm{P}_{2} \mathrm{Y}_{12}$ receptor. In light of new data, this review provides an update on the pharmacokinetic, pharmacodynamic and pharmacogenetic profiles of ticagrelor in different study populations. Recent studies report that no dose adjustment for ticagrelor is required on the basis of age, gender, ethnicity, severe renal impairment or mild hepatic impairment. The non-P2 $\mathrm{Y}_{12}$ actions of ticagrelor are reviewed, showing indirect positive effects on cellular adenosine concentration and biological activity, by inhibition of equilibrative nucleoside transporter- 1 independently of the $\mathrm{P}_{2} \mathrm{Y}_{12}$ receptor. CYP2C19 and ABCB1 genotypes do not appear
\end{abstract}

Renli Teng

renli.teng@astrazeneca.com

1 AstraZeneca LP, Gaithersburg, MD, USA to influence ticagrelor pharmacodynamics. A summary of drug interactions is also presented.

\section{Key Points}

Dual antiplatelet therapy with aspirin and a $\mathrm{P} 2 \mathrm{Y}_{12}$ receptor inhibitor represents the standard of care treatment for the management of patients with acute coronary syndrome.

Ticagrelor is the first of a new class of $\mathrm{P}_{2} \mathrm{Y}_{12}$ receptor inhibitors, which is distinct from clopidogrel and prasugrel with respect to its unique mode of action.

This article provides a comprehensive overview of the pharmacokinetic, pharmacodynamic and pharmacogenetic profiles of ticagrelor in different study populations - updating a previous review on this topic.

\section{Introduction}

Acute coronary syndromes (ACS) encompass a spectrum of unstable coronary artery disease (CAD), involving an abrupt reduction in coronary blood flow leading to myocardial ischaemia and/or myocardial infarction (MI) with or without ST-segment elevation [1]. Associated with significant morbidity and mortality [2], the pathophysiology of the majority of these life-threatening conditions involves the rupture of an atherosclerotic plaque within a 
coronary artery and subsequent platelet activation, aggregation and thrombus formation [3]. Myocardial injury can also occur through increased oxygen demand (e.g. stenosis) or via non-atherothrombotic coronary obstruction (e.g. arteriospasm) [4]. If untreated, decreased blood flow and decreased perfusion of the myocardium can lead to myocardial necrosis [2]. Dual antiplatelet therapy represents the cornerstone of treatment for ACS. Guidelines recommend aspirin plus a $\mathrm{P} 2 \mathrm{Y}_{12}$ receptor antagonist, with selection of the $\mathrm{P}_{2} \mathrm{Y}_{12}$ inhibitor dependent on individual patient characteristics, such as advanced age, and concomitant use of immunosuppressant agents [1, 5-7]. The two classes of $\mathrm{P}_{2} \mathrm{Y}_{12}$ receptor antagonist currently available for antiplatelet therapy are thienopyridines (clopidogrel and prasugrel) and, more recently, the cyclopentyltriazolopyrimidines (ticagrelor). Although widely available in generic form, and previously considered standard therapy for ACS [8], clopidogrel is associated with a number of limitations, including a delayed onset of action due to the need for metabolic activation, prolonged recovery of platelet function due to irreversible $\mathrm{P}^{2} \mathrm{Y}_{12}$ platelet binding, and variable and reduced antiplatelet effects in patients with certain genotypes, which may be related to genetic variations in the enzymes responsible for clopidogrel metabolic activation [9-11]. Like clopidogrel, prasugrel requires metabolic activation for antiplatelet activity and binds irreversibly [12]. The antiplatelet response to prasugrel appears to be more potent and consistent compared with the response to clopidogrel. However, as shown in TRITON-TIMI 38 (Trial to Assess Improvement in Therapeutic Outcomes by Optimizing Platelet Inhibition with Prasugrel-Thrombolysis in Myocardial Infarction 38), these positive effects are accompanied by an increase in the rate of major bleeding [13].

The $\mathrm{P}_{2} \mathrm{Y}_{12}$ receptor antagonist ticagrelor has a unique mode of action [14]. Ticagrelor does not require metabolic activation for antiplatelet activity and binds reversibly to the $\mathrm{P}_{2} \mathrm{Y}_{12}$ receptor. In the PLATO (Platelet Inhibition and Patient Outcomes) study, ticagrelor significantly reduced the incidence of the composite end point of cardiovascular death, MI or stroke in patients with ACS, compared with clopidogrel [15]. There were no significant differences in overall major bleeding rates between treatments, although a significantly higher rate of major bleeding not related to coronary artery bypass grafting (CABG) was seen with ticagrelor versus clopidogrel [15]. The prospective PEGASUS-TIMI 54 study showed that long-term therapy with ticagrelor and low-dose aspirin in patients with a prior MI ( $>12$ months previously) significantly reduced the incidence of the primary efficacy end point (a composite of cardiovascular death, MI or stroke), with an increase in major bleeding versus placebo [16].

Assessing the pharmacological profile of oral antiplatelet agents is critical for the appropriate selection of an antiplatelet agent and/or regimen, particularly given the broad patient population with ACS, with the potential range of comorbidities [6,7]. This article provides a comprehensive summary of the pharmacokinetic, pharmacodynamic and pharmacogenetic profiles of ticagrelor, updating an earlier review on this topic [17].

\section{Ticagrelor Pharmacokinetic Profile}

\subsection{Absorption, Distribution, Metabolism and Excretion}

The pharmacokinetic profile of ticagrelor has been evaluated in healthy volunteers and in patients with CAD, atherosclerosis and ACS. A regional absorption study in healthy volunteers showed that the proportion of ticagrelor that was absorbed decreased the further down the gastrointestinal tract that the dose was released [18]. In healthy volunteers, single oral doses of ticagrelor 0.1-400 mg were rapidly absorbed, with a median time to reach the maximum plasma concentration $\left(t_{\max }\right)$ of approximately $1.3-2 \mathrm{~h}$. Similarly, the median $t_{\max }$ for AR-C124910XX (the active metabolite of ticagrelor) was 1.5-3 h [19, 20]. Alternative methods of administration have been shown to increase the rate of absorption of ticagrelor. In healthy volunteers, administration of ticagrelor as a crushed tablet (dosed orally or via a nasogastric tube) increased plasma concentrations of ticagrelor and AR-C124910XX at early time points (0.5 and $1 \mathrm{~h}$ post-dose) relative to oral administration of a whole tablet. The ticagrelor $t_{\max }$ was shorter following crushed versus whole tablet administration (1 vs 2 h) (Fig. 1) [21]. Further studies are warranted to assess whether administration of crushed tablets provides a pharmacodynamic or clinical benefit in scenarios in which the absorption of ticagrelor occurs less rapidly than predicted, e.g. in patients with ACS, in whom $t_{\max }$ values of 3 and $4 \mathrm{~h}$ have been reported for ticagrelor and AR-C124910XX, respectively, following a $180 \mathrm{mg}$ loading dose [22].

The mean absolute bioavailability of ticagrelor in healthy volunteers is $36 \%$ [18]. Mean and maximum plasma concentration $\left(C_{\max }\right)$ values of ticagrelor and ARC124910XX increase linearly and predictably in a dosedependent manner and are stable at steady state in healthy volunteers [23] and in patients with atherosclerosis [24], CAD [25] and ACS [22]. The effect of food on exposure to ticagrelor and AR-C124910XX is small and considered to 


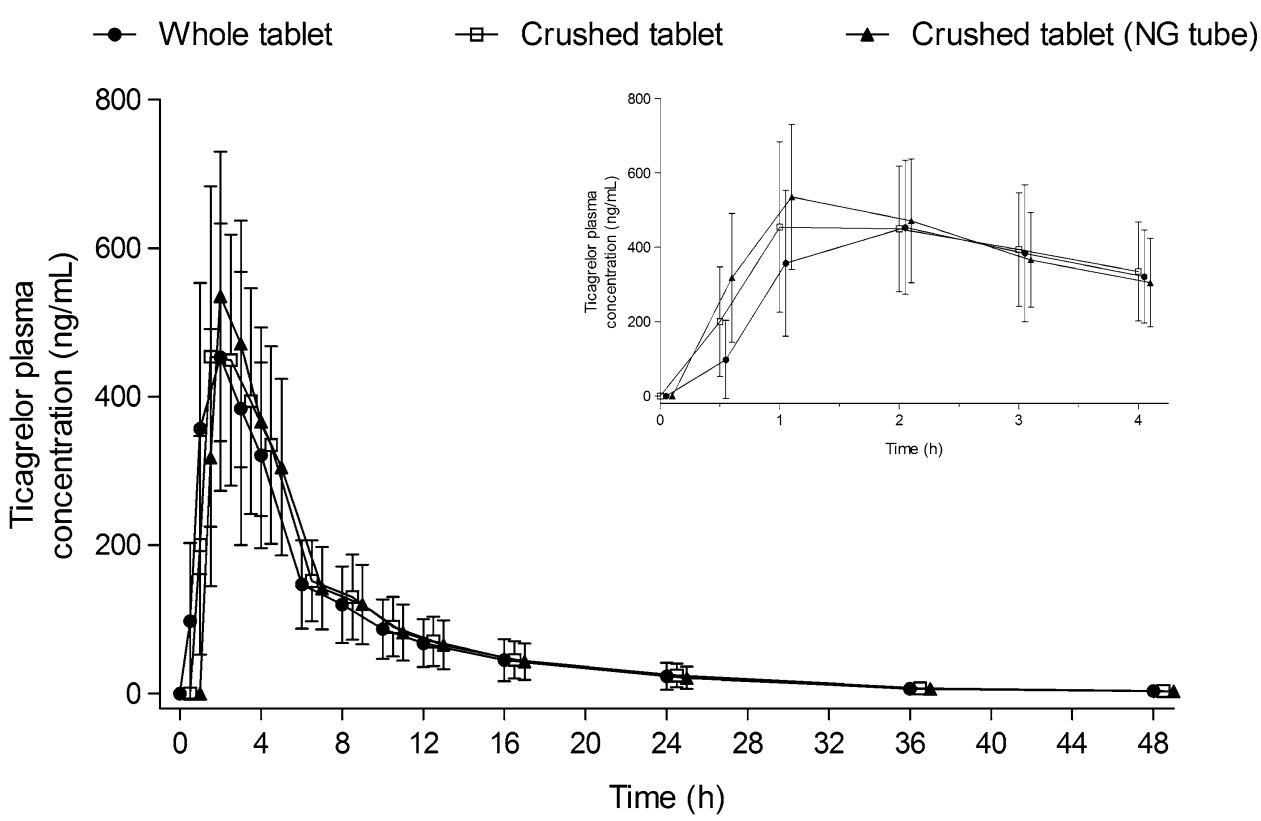

Fig. 1 Arithmetic mean \pm standard deviation plasma concentrations of ticagrelor over time following administration of a $90 \mathrm{mg}$ dose of ticagrelor administered either orally as a whole tablet, orally as a crushed tablet or as a crushed tablet via a nasogastric (NG) tube [21]. Compared with a whole tablet: $p<0.0001$ for crushed tablet (NG

be of minimal clinical significance. Therefore, ticagrelor can be administered with or without food [26].

In vitro studies evaluating the metabolism of ticagrelor have been conducted in hepatocyte and microsomal preparations from several animal species [27]. Multiple metabolites were identified and the major metabolites across all species were AR-C124910XX and ARC133913XX. Cytochrome P450 (CYP) 3A4 and CYP3A5 were primarily responsible for the formation of ARC124910XX, whereas the formation of AR-C133913XX most likely occurred via CYP3A4, with a lesser contribution from CYP3A5 [28]. Consequently, potential interactions between ticagrelor and inducers or inhibitors of CYP3A4 were evaluated in clinical pharmacology studies and are discussed in greater detail in the 'Drug Interactions' section.

Experiments conducted with radiolabelled ticagrelor in six healthy male volunteers identified ten discrete metabolites, with unchanged ticagrelor and ARC124910XX being the predominant entities observed in the plasma. AR-C124910XX is present at approximately $30-40 \%$ of the concentration of the parent compound [20, 24]. Following administration of $\left[{ }^{14} \mathrm{C}\right]$-ticagrelor, $58 \%$ was recovered in the faeces and $27 \%$ in the urine; the levels of unchanged ticagrelor and AR-C124910XX in the urine were $<0.05 \%$ [20]. These data indicate that ticagrelor is mainly excreted in the faeces, with renal excretion tube) at 0.5 and $1 \mathrm{~h}$ post-dosing and for crushed tablet at $0.5 \mathrm{~h}$ postdosing; $p<0.02$ for crushed tablet at $1 \mathrm{~h}$ post-dosing (linear mixedeffects model with sequence, period and treatment as fixed effects, and volunteer nested within sequence as a random effect). (From: Teng et al. [21]. With kind permission from Dustri-Verlag)

playing only a minor role; the primary route of excretion for the active metabolite is most likely biliary secretion.

The mean elimination half-life of ticagrelor is 7.7-13.1 h, whereas the mean elimination half-life of ARC124910XX is $7.5-12.4 \mathrm{~h}$ [19]. Table 1 summarizes the key pharmacokinetic parameters of ticagrelor alongside clopidogrel and prasugrel.

\subsection{Ticagrelor Pharmacokinetics in Special Populations}

In 40 healthy volunteers who received ticagrelor $200 \mathrm{mg}$, systemic exposure to ticagrelor and AR-C124910XX was approximately 40-60\% higher in elderly versus young subjects and in women versus men. However, no dose adjustment is considered necessary on the basis of either age or gender [32]; nor is dose adjustment required in patients with severe renal impairment [33] or mild hepatic impairment [34]. The use of ticagrelor is contraindicated in patients with severe hepatic impairment [29]. As ticagrelor metabolism occurs in the liver [27, 28], exposure to the parent drug will probably increase in severe hepatic impairment [29]. In addition, the bleeding risk is increased in severe hepatic impairment because of reduced synthesis of coagulation proteins [29]. No pharmacokinetic data are available in patients with moderate hepatic impairment (need to consider the risk-benefit of ticagrelor due to 
Table 1 Summary of key pharmacokinetic and pharmacodynamic parameters of $\mathrm{P} 2 \mathrm{Y}_{12}$ receptor inhibitors

\begin{tabular}{|c|c|c|c|}
\hline End point & Ticagrelor $[19,20,29]$ & Clopidogrel $[29,30]$ & Prasugrel [31] \\
\hline Metabolic activation required & $\begin{array}{l}\text { No } \\
\text { Major metabolite (AR-C124910XX) is } \\
\text { equipotent to the parent compound }\end{array}$ & Yes & Yes \\
\hline $\begin{array}{l}\text { Reversibility of binding to ADP receptor } \\
\text { Single-dose pharmacokinetic parameters }\end{array}$ & Reversible & Irreversible & Irreversible \\
\hline$t_{\max }$ & $\begin{array}{l}\text { Ticagrelor: } 1.3-2 \mathrm{~h} \\
\text { AR-C124910X: } 1.3-3 \mathrm{~h}\end{array}$ & $30-60 \min ^{\mathrm{a}}$ & $30 \min ^{\mathrm{a}}$ \\
\hline$t_{1 / 2}$ & $\begin{array}{l}\text { Ticagrelor: } 7.7-13.1 \mathrm{~h} \\
\text { AR-C124910X: } 7.5-12.4 \mathrm{~h}\end{array}$ & $30 \min ^{\mathrm{a}}$ & $7(2-15) \mathrm{h}^{\mathrm{a}}$ \\
\hline Onset of IPA & & & \\
\hline $40-50 \%$ IPA & $30 \mathrm{~min}$ & $2-4 \mathrm{~h}$ & $1 \mathrm{~h}$ \\
\hline Maximum IPA & $2 \mathrm{~h}$ & $8 \mathrm{~h}$ & $3 \mathrm{~h}$ \\
\hline Duration of IPA & $3-5$ days & $7-10$ days & 5-10 days \\
\hline
\end{tabular}

$A D P$ adenosine 5 -diphosphate, $I P A$ inhibition of platelet aggregation, $t_{1 / 2}$ elimination half-life, $t_{\max }$ time to reach maximum plasma concentration

${ }^{a}$ Data are for the active metabolite

probable increase in exposure [29]) or patients receiving renal dialysis.

In PLATO, the incidence of dyspnoea was higher with ticagrelor compared with clopidogrel [15, 29]. Ticagrelor inhibits platelet activity via $\mathrm{P}_{2} \mathrm{Y}_{12}$ receptor inhibition and also via adenosine [35]. A potential mechanism of ticagrelor-induced dyspnoea involves increased endogenous levels of adenosine [36]. Adenosine can induce dyspnoea in normal [37] and asthmatic [38] subjects. Thus, two randomized, double-blind, placebo-controlled, two-way crossover studies were conducted to evaluate the pharmacokinetics, pharmacodynamics and safety of ticagrelor in subjects at risk of respiratory impairment (healthy elderly) and in patients with respiratory impairment (mild asthma or mild to moderate chronic obstructive pulmonary disease [COPD]) [39]. Although exposure to ticagrelor (at steady state) and AR-C124910XX (after a single dose of ticagrelor and at steady state) appeared to be lower in patients with asthma or COPD compared with healthy elderly volunteers, no consistent relationship was observed between exposure and minute ventilation, respiratory rate, tidal volume, spirometry, pulse oximetry or dyspnoea. Furthermore, ticagrelor did not appear to alter pulmonary function at rest or during exercise; bronchospasm (as determined by spirometry and pulse oximetry) was not observed in any cohort [39]. Additionally, diabetic status appears to have no significant effect on ticagrelor pharmacokinetics (AstraZeneca, data on file) [40].

The pharmacokinetics of ticagrelor have also been assessed in several different ethnic groups. Ticagrelor and ARC124910XX exhibited linear and predictable pharmacokinetics in healthy Chinese volunteers at doses of 90 and
$180 \mathrm{mg}$ [41]. Exposures to ticagrelor and AR-C124910XX at steady state were slightly higher in Chinese volunteers compared with Caucasian volunteers in other studies [19, 20]. The pharmacokinetics of ticagrelor and AR-C124910XX in Japanese volunteers were assessed in two ethnicity-bridging studies. Pharmacokinetic profiles were broadly comparable between Japanese and Caucasian volunteers following single ascending doses (50-600 mg) and multiple ascending doses (100 or $300 \mathrm{mg}$ ) of ticagrelor [42]. After adjustments to account for differences in body weight between the ethnic groups, exposure to ticagrelor and AR-C124910XX was approximately $20 \%$ greater in Japanese versus Caucasian participants [42]. These findings were consistent with observations in a similar study of Japanese patients with CAD [43]. In DISPERSE (Dose Confirmation Study Assessing AntiPlatelet Effects of AZD6140 vs Clopidogrel in Non-ST-segment Elevation Myocardial Infarction), after treatment with ticagrelor (45 or $90 \mathrm{mg}$ twice daily) for 28 days, the area under the plasma concentration-time curve $\left(\mathrm{AUC}_{\tau}\right)$ and $C_{\max }$ of ticagrelor and AR-C124910XX were 1.3- to 1.5 -fold greater in Japanese patients than in Caucasian patients (Fig. 2) $[24,43]$. The observed differences in exposure to ticagrelor in Chinese and Japanese versus Caucasian patients are not of sufficient magnitude to warrant dose adjustment on the basis of ethnicity.

Two randomized, open-label, crossover studies evaluated the pharmacokinetic parameters of ticagrelor in Hispanic and African-American patients with CAD [44, 45]. Ticagrelor and AR-C124910XX exhibited similar exposure in Hispanic and African-American patients compared with those previously reported in Caucasian patients $[25,44$, 45]. 
Fig. 2 Scatter plot of ticagrelor plasma concentration vs finalextent inhibition of platelet aggregation (IPA) in Japanese patients with stable coronary artery disease. The prediction curve shown in the figure is based on a sigmoid maximum effect $\left(E_{\max }\right)$ model [43]. (From: Hiasa et al. [43]. With kind permission from Springer Science and Business Media)

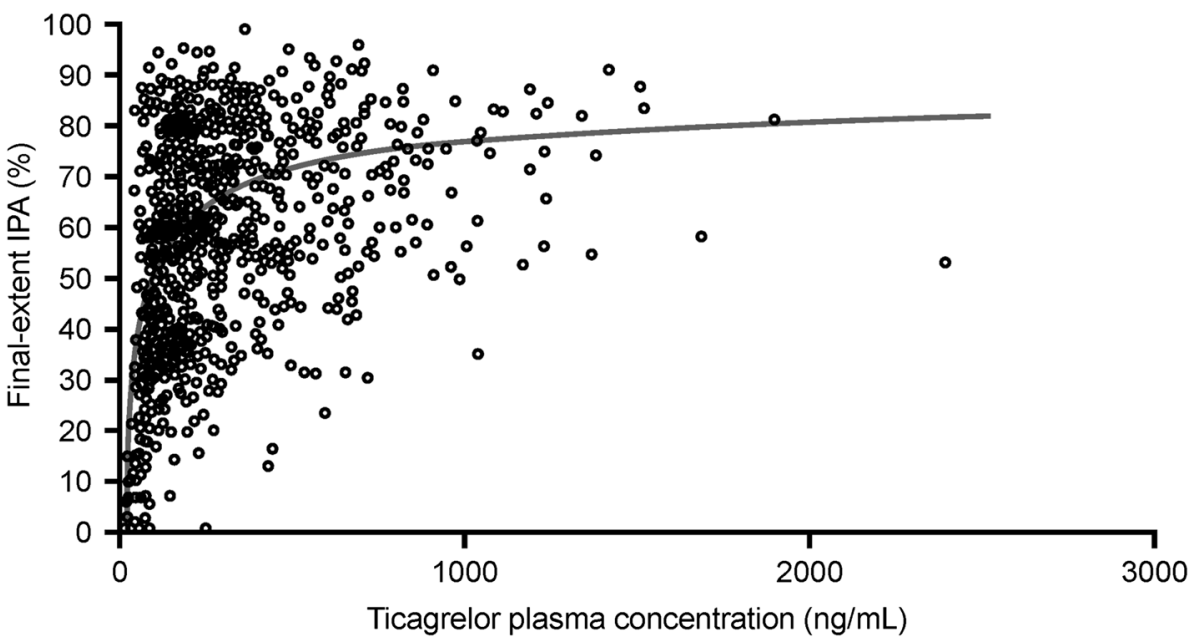

\subsection{Drug Interactions}

In vitro experiments using human liver microsomes indicate that ticagrelor and AR-C124910XX are predominantly metabolized by CYP3A4 and, less so, by CYP3A5 enzymes [20, 28]. Metabolism studies demonstrate that, in addition to being a CYP3A substrate, ticagrelor is a weak inhibitor or activator of CYP3A [28]. Ticagrelor and ARC124910XX appear to have low or no potential to induce CYP1A1, CYP1A2, CYP2C9, CYP2B6 and CYP3A4, and no propensity to inhibit CYP1A2, CYP2B6, CYP2C8, CYP2C19, CYP2D6 and CYP2E1. Unpublished in vitro studies also indicate that ticagrelor is a substrate and inhibitor of P-glycoprotein (P-gp) [29].

\subsubsection{Effects of Ticagrelor on the Pharmacokinetics of Other Products}

The interaction of ticagrelor and the probe CYP3A substrate midazolam was evaluated in healthy volunteers in two clinical pharmacology studies [46] and confirmed earlier unpublished in vitro findings that ticagrelor is a weak inhibitor of CYP3A. Thus, co-administration of ticagrelor with CYP3A substrates that have a narrow therapeutic profile (e.g. ergot alkaloids, cisapride) should be avoided [29]. Statin compounds are also substrates of CYP3A and concomitant administration with antiplatelet agents is common in patients with ACS $(90 \%$ of patients receiving ticagrelor in the PLATO study received concomitant statins with no safety concerns) [15]. Two separate crossover studies evaluated the interaction between ticagrelor (loading dose $270 \mathrm{mg} ; 180 \mathrm{mg}$ twice daily, 7 days) and atorvastatin $(80 \mathrm{mg})$ or simvastatin $(80 \mathrm{mg})$ [47]. Co-administration with ticagrelor increased the atorvastatin $C_{\max }$ by $23 \%$ and AUC by $36 \%$. These increases in $C_{\max }$ were modest and considered not to be clinically significant. However, the magnitude of the interaction between ticagrelor and simvastatin was greater. The mean simvastatin $C_{\max }$ and AUC increased by 81 and $56 \%$, respectively, in the presence of ticagrelor and, in some individuals, 2- to 3-fold increases in the simvastatin AUC were observed. Although the dose of ticagrelor used in these studies was greater than the clinically approved regimen, it is recommended that the concomitant use of simvastatin or lovastatin at doses greater than $40 \mathrm{mg}$ should be avoided with ticagrelor, as patients may be at increased risk of statin-related adverse effects [29, 47].

CYP isoenzymes, including $3 \mathrm{~A} 4$, also play a role in the oxidative metabolism of ethinyl oestradiol and the hydroxylation of levonorgestrel. As it is common for combinations of these compounds to be used in widely dispensed oral contraceptives, potential interactions with ticagrelor were assessed in young, healthy women (mean [standard deviation] age 32.7 [7.1] years) [48]. Co-administration of ticagrelor had no significant effects on the pharmacokinetics of ethinyl oestradiol or levonorgestrel; thus, no clinically relevant effect of ticagrelor on oral contraceptive efficacy or safety is expected [48].

One of the most abundant hepatic CYP enzymes involved in the absorption, distribution, metabolism and excretion of ticagrelor is CYP2C9. No interaction between ticagrelor and the model CYP2C9 substrate tolbutamide was observed in healthy volunteers [49]. Thus, ticagrelor is unlikely to affect CYP2C9-mediated metabolism of other drugs and vice versa. As such, a recent European Society of Cardiology expert position paper concluded that proton pump inhibitors (which are predominantly metabolized by CYP2C enzymes) are unlikely to have any significant pharmacokinetic interaction with ticagrelor [50]. Similarly, ticagrelor is not expected to affect CYP2D6-mediated drug metabolism to a clinically relevant extent. In healthy volunteers, co-administration of ticagrelor with the CYP2D6 
substrate venlafaxine resulted in only a small (22\%) increase in the venlafaxine $C_{\max }$ and no significant increase in the venlafaxine AUC [51].

In addition to the CYP enzymes, various transporter proteins also play a role in the absorption, distribution, metabolism and excretion of drugs. As suggested by unpublished in vitro studies, ticagrelor is a weak inhibitor of P-gp. Concomitant use of ticagrelor and digoxin increased exposure to digoxin ( $C_{\max }$ by $75 \%$, AUC by $28 \%$ ) [52]. Therefore, appropriate clinical and/or laboratory monitoring is recommended when ticagrelor is administered with P-gp-dependent drugs possessing a narrow therapeutic profile (e.g. digoxin).

\subsubsection{Effects of Other Products on the Pharmacokinetics of Ticagrelor}

Ticagrelor is a substrate of CYP3A and the use of ticagrelor with strong CYP3A4 inhibitors or potent CYP3A inducers was thus an exclusion criterion in the PLATO study [15]. Concomitant administration of strong CYP3A inducers (e.g. rifampicin) decreases exposure to ticagrelor. For example, co-administration of ticagrelor and rifampicin significantly reduced the $C_{\max }$, AUC and plasma half-life of ticagrelor by 73, 86 and $67 \%$, respectively [53]. Conversely, strong CYP3A4 inhibitors (e.g. ketoconazole, ritonavir) or moderate CYP3A4 inhibitors (e.g. diltiazem, fluconazole, grapefruit juice) increase exposure to ticagrelor. For example, in healthy volunteers, grapefruit juice increased the ticagrelor $C_{\max }$ and AUC by 165 and $221 \%$, respectively [54]. Moreover, co-administration of ketoconazole increased the ticagrelor $C_{\max }$ and AUC by 135 and $632 \%$, respectively [55]. On the basis of these findings, the use of ticagrelor with strong CYP3A4 inhibitors is contraindicated [29, 55].

Cyclosporine is a weak inhibitor of CYP3A4, as well as a potent inhibitor of P-gp. As it is possible that ticagrelor (a CYP3A4 and P-gp substrate) might be co-administered with cyclosporine in patients with ACS and comorbidities requiring immunosuppressive treatment, a crossover study was performed in healthy volunteers to evaluate potential interactions. Co-administration of ticagrelor with cyclosporine increased the ticagrelor AUC and $C_{\max }$ by 283 and $230 \%$, respectively, while the pharmacokinetic profile of cyclosporine was unaffected. However, the magnitude of cyclosporine's effect on ticagrelor pharmacokinetics was not considered sufficient to warrant dose adjustment of ticagrelor [56].

The interaction of ticagrelor with two anticoagulants, heparin and enoxaparin, was evaluated in two studies of healthy volunteers, and no notable changes in the pharmacokinetics of ticagrelor or AR-C124910XX were reported [57]. Furthermore, switching from clopidogrel to ticagrelor did not substantially affect the pharmacokinetic profile of ticagrelor [25].

A summary of known ticagrelor drug interactions is provided in Table 2 .

\subsubsection{Clinical Outcomes in PLATO in Patient Subgroups Taking Co-administered Drugs}

The majority of ACS patients in the PLATO study were taking a range of co-administered drugs typical of this patient population [15]. In predefined subgroups, ticagrelor significantly reduced the incidence of the primary end point (a composite of cardiovascular death, MI or stroke) compared with clopidogrel in patients taking lipid-lowering drugs, beta-blockers, angiotensin-converting enzyme inhibitors and calcium channel blockers. The incidence of the primary end point was also lower (not significant) with ticagrelor versus clopidogrel in patients taking angiotensin II receptor blockers or proton pump inhibitors. PLATO also demonstrated that ticagrelor was associated with better clinical outcomes versus clopidogrel in patients on lowdose maintenance aspirin [58]. Consequently, aspirin doses $<100 \mathrm{mg}$ /day are recommended with ticagrelor [29].

\section{Ticagrelor Pharmacodynamic Profile}

Table 1 summarizes the key pharmacodynamic parameters of ticagrelor alongside clopidogrel and prasugrel.

\subsection{Mechanism of Action}

\subsubsection{P2Y $\mathrm{Y}_{12}$ Receptor Binding}

Ticagrelor binds to $\mathrm{P} 2 \mathrm{Y}_{12}$ receptors in a potent and reversible manner using a binding site distinct from the adenosine 5'-diphosphate (ADP)-binding site [14]. Consequently, binding does not cause an ADP-induced conformational change in the $\mathrm{P} 2 \mathrm{Y}_{12}$ receptor, $\mathrm{G}$ proteins are not activated, the receptor remains inactive and ADP signalling is inhibited [59]. Ticagrelor binds only to the $\mathrm{P} \mathrm{Y}_{12}$ receptor and not to other P2Y receptor types [60]. Unlike clopidogrel and prasugrel, ticagrelor does not require metabolic activation and its active metabolite, ARC124910XX, is approximately equipotent to ticagrelor at the $\mathrm{P}_{2} \mathrm{Y}_{12}$ receptor. AR-C124910XX is also thought to contribute to the antiplatelet effect reported with ticagrelor administration [20].

Reticulated platelets are large, young, newly formed platelets and have been shown to exhibit increased reactivity, compared with non-reticulated platelets [61]. Platelet recovery was tested in rats receiving a single dose of 


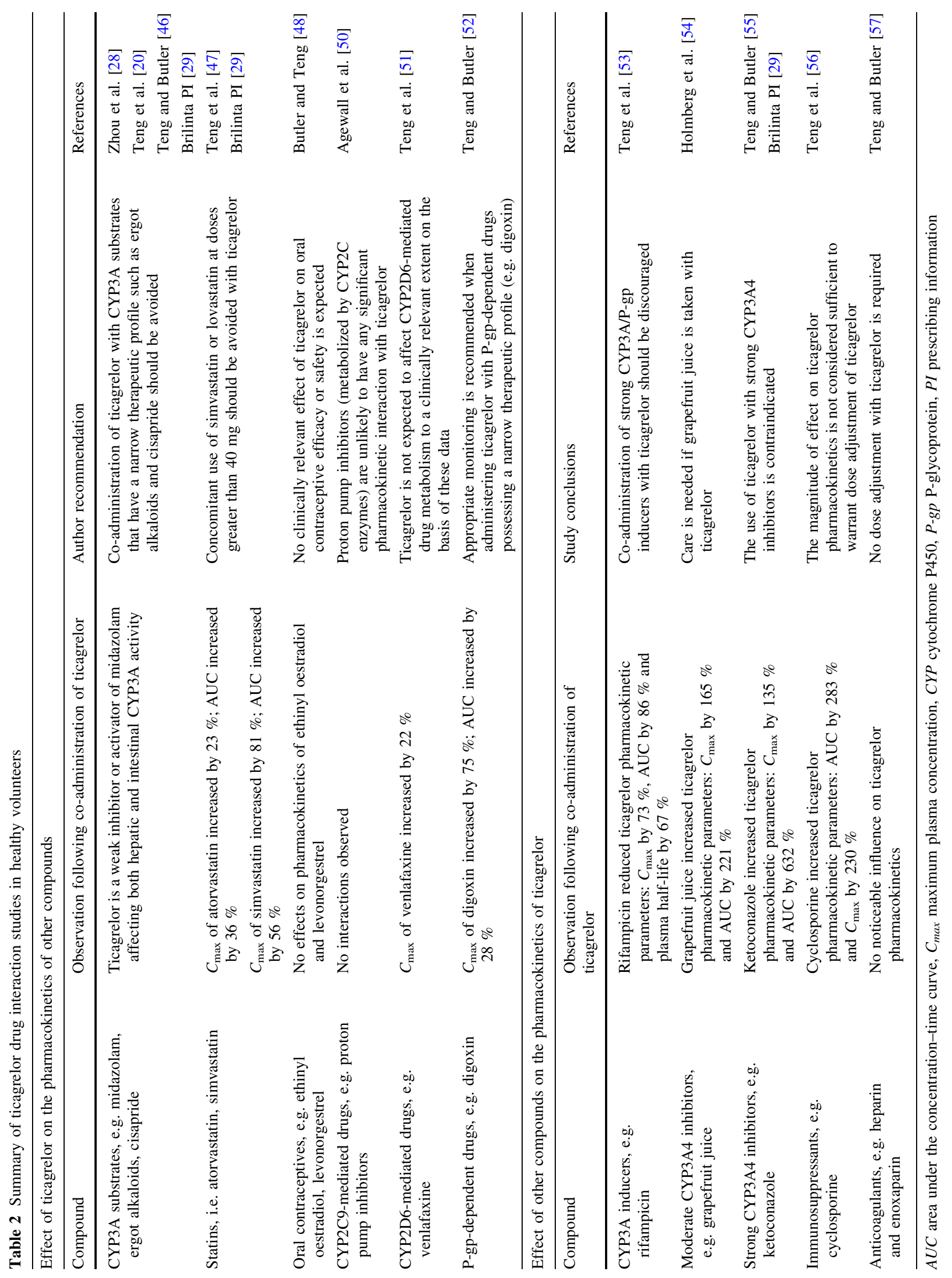


ticagrelor $(40 \mathrm{mg} / \mathrm{kg})$ or clopidogrel $(200 \mathrm{mg} / \mathrm{kg})$. Ticagrelor reduced thrombus formation more effectively compared with clopidogrel [62]. The study reported that a subpopulation of juvenile platelets, which formed at later time points, promoted thrombus formation after clopidogrel but not after ticagrelor. This suggests that, at least in rats, the recovery of platelet function after treatment with ticagrelor differs mechanistically from that after treatment with clopidogrel.

The efficacy of antiplatelet therapy must be balanced with the risk of bleeding in situations such as planned or emergency surgery. The vasopressin desmopressin is often used as a first-line therapy for individuals with bleeding disorders. The effect of desmopressin on bleeding time in healthy volunteers receiving ticagrelor was tested in a randomized, double-blind, two-way crossover study [63]. Healthy volunteers received ticagrelor (270 mg loading dose; $180 \mathrm{mg}$ twice daily) for 5 days; at day 5, desmopressin $(0.3 \mathrm{mcg} / \mathrm{kg})$ or saline intravenous infusions were then administered. The study reported no significant effect of desmopressin on bleeding time or inhibition of platelet aggregation (IPA). However, primary haemostatic activity was increased [63]. To date, no pharmacological agent has been shown to reverse the antiplatelet effect of ticagrelor. Currently, a specific antidote to ticagrelor is under development [64]. This antidote, MEDI2452, is a highly specific neutralizing fragment antigen binding (Fab) and reversed the antiplatelet activity of ticagrelor in vitro (in human platelet-rich plasma) and in vivo (in a mouse model of acute surgery) [64]. MEDI2452 requires further investigation to assess its potential role in reversal of the antiplatelet effects of ticagrelor in humans.

Platelet-rich plasma may reverse the antiplatelet effects of clopidogrel [65], although a more recent study demonstrated that autologous platelet transfusion did not reverse the effects of clopidogrel $24 \mathrm{~h}$ after the final dose [66]. A study of the effect of autologous platelet transfusion in healthy volunteers treated with ticagrelor was recently completed (ClinicalTrials.gov study ID: NCT01744288) and the results are to be published.

\subsubsection{Effects of Ticagrelor on Adenosine}

The clinical characteristics of ticagrelor may be related to its effect not only through the $\mathrm{P}_{2} \mathrm{Y}_{12}$ receptor but also through adenosine-mediated action [35]. Using an in vitro model with recombinant Madin-Darby canine kidney cells, at concentrations of clinical relevance, ticagrelor-and, to a lesser extent, its metabolites-inhibited cellular adenosine uptake in cells expressing equilibrative nucleoside transporter-1 (ENT-1) [67]. In the same study, the active metabolites of clopidogrel and prasugrel did not display any significant inhibition of ENT-1. This finding was supported by a clinical study examining coronary blood flow velocity (CBFV) in healthy men receiving ticagrelor or placebo, which showed that ticagrelor enhanced adenosine-induced CBFV and the sensation of dyspnoea [68]. The inhibition of ENT-1 by ticagrelor has been reported from other studies and has been recently reviewed [69]. ENT-1 inhibition protects adenosine from intracellular metabolism, thereby increasing its concentration and biological activity, providing potential benefit for the heart in ischaemia-reperfusion injury [69].

\subsubsection{Other Pleiotropic Effects of Ticagrelor}

In addition to the ENT-1-mediated effects of ticagrelor, a comparison of the effect of clopidogrel and ticagrelor on myocardial infarct size in rats showed that ticagrelor, but not clopidogrel, reduces myocardial infarct size [70]. The effect of ticagrelor was dependent on adenosine-receptor activation with downstream upregulation of endothelial nitric oxide synthase and cyclooxygenase- 2 activity. An in vitro investigation of the effects of ticagrelor and the clopidogrel-active metabolite showed that ticagrelor has an anticoagulant and anti-inflammatory profile and enhances endothelial nitric oxide synthase activation [71]. These effects appeared to be mediated independently of $\mathrm{P}_{2} \mathrm{Y}_{12}$ or adenosine receptors.

\subsection{Inhibition of Platelet Activity: Data from Clinical Studies}

\subsubsection{Healthy Volunteer Studies}

Ticagrelor inhibited ADP-induced platelet aggregation in a dose-dependent manner in healthy volunteers receiving single 30-400 mg doses, with doses less than $30 \mathrm{mg}$ having no significant inhibitory effect [19]. When given twice daily $(50-300 \mathrm{mg}$ ), ticagrelor provides a consistently greater IPA than an equivalent single daily dose (100-600 mg) [23]. In the study of single and multiple ascending doses of ticagrelor in Japanese and Caucasian healthy volunteers, a slightly greater exposure in Japanese versus Caucasian groups was reported, although pharmacodynamic responses in terms of IPA and bleeding time were similar between groups [42].

\subsubsection{Patients with Coronary Artery Disease}

In Japanese and non-Japanese Asian patients with stable CAD receiving ticagrelor (45 or $90 \mathrm{mg}$ twice daily) or clopidogrel (75 mg once daily), IPA was dose dependent and was greater with ticagrelor versus clopidogrel. In a subset of Japanese patients, exposure to ticagrelor and its active metabolite, AR-C124910XX, increased dose 

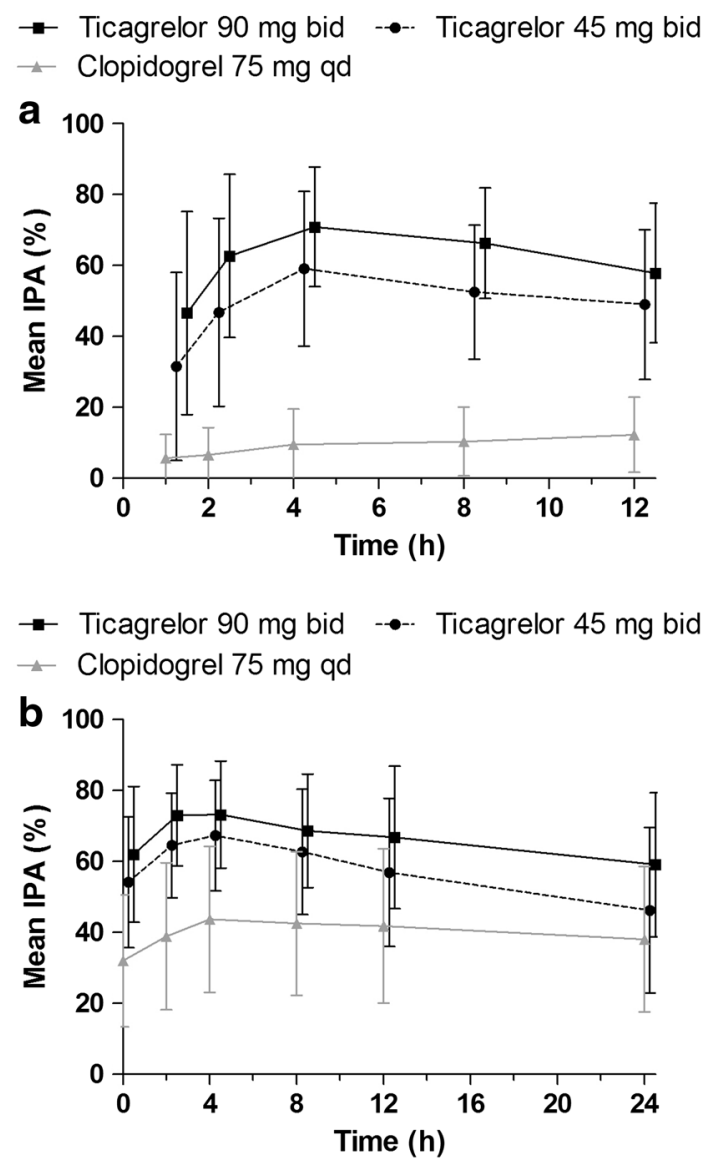

Fig. 3 Mean ( \pm standard deviation) final-extent inhibition of platelet aggregation (IPA) on a day 1 and $\mathbf{b}$ day 28 in Japanese patients with stable coronary artery disease treated with low-dose aspirin plus ticagrelor $45 \mathrm{mg}$ twice daily (bid), ticagrelor $90 \mathrm{mg}$ bid or clopidogrel $75 \mathrm{mg}$ once daily (qd) [43]. (From: Hiasa et al. [43]. With kind permission from Springer Science and Business Media)

proportionally (Fig. 3) [43]. Further comparator studies of ticagrelor versus clopidogrel in Hispanic and AfricanAmerican patients reported similar results $[44,45]$. Clinical trials report poorer outcomes for diabetic patients with ACS compared with patients without diabetes [72]. The presence of diabetes does not appear to influence response to ticagrelor. Consistent with the full study population analysis reported above, subgroup analyses in Hispanic (AstraZeneca, data on file) and African-American [40] patients with diabetes also reported greater IPA with ticagrelor versus clopidogrel.

In patients with stable atherosclerosis, greater IPA was observed for ticagrelor compared with clopidogrel [24]. Higher doses of ticagrelor (100 and $200 \mathrm{mg}$ twice daily, and $400 \mathrm{mg}$ once daily) provided more effective IPA than ticagrelor $50 \mathrm{mg}$ twice daily or clopidogrel $75 \mathrm{mg}$ once daily at $2 \mathrm{~h}$ after initial dosing and at steady state. Furthermore, $4 \mathrm{~h}$ post-dosing at steady state, the greater IPA observed with the higher doses of ticagrelor compared with ticagrelor $50 \mathrm{mg}$ twice daily or clopidogrel $75 \mathrm{mg}$ was maintained [24].

\subsubsection{Patients with Acute Coronary Syndromes}

The PLATO study, a multicentre, double-blind, randomized trial of ticagrelor (180 mg loading dose, $90 \mathrm{mg}$ twice daily thereafter) versus clopidogrel ( $75 \mathrm{mg}$ once daily), in patients with ACS, reported no significant differences in overall major bleeding events (PLATO- and TIMI-defined bleeding), or fatal or life-threatening bleeding, or rates of CABG-related major bleeding, or bleeding requiring a transfusion between treatment groups [15]. Compared with clopidogrel, rates of non-CABG-related major bleeding and fatal intracranial bleeding were higher with ticagrelor. For other types of fatal bleeding, rates were lower with ticagrelor versus clopidogrel. In the subgroup of ACS patients in PLATO who were undergoing CABG and who stopped taking antiplatelet therapy $\leq 1$ to $>6$ days prior to surgery, there was no difference in CABG-related major bleeding between ticagrelor and clopidogrel [73]. The ticagrelor prescribing information [29] and current guidelines [1, 5-7] recommend that ticagrelor is discontinued at least $24 \mathrm{~h}$ before urgent CABG [1,5] and 3-5 days [7] or at least 5 days $[1,5,6,29]$ prior to planned CABG.

A substudy of the PLATO trial showed greater IPA with ticagrelor versus clopidogrel, with separation of profiles reported within the first hours of treatment and also during maintenance therapy [74]. Consistent with the results of the PLATO study, in the DISPERSE-2 study of ticagrelor versus clopidogrel in patients with non-ST-segment elevation ACS, there was no difference between groups in major bleeding rates [75]. Although not significant, a trend for a reduction in MI rates was seen for ticagrelor versus clopidogrel in the DISPERSE-2 substudy. In a further study of 50 patients with ST-segment elevation MI (STEMI), ticagrelor and prasugrel effects on platelet reactivity were not significantly different [76]. Interestingly, in this study, morphine use was associated with delayed activity of ticagrelor and prasugrel.

Some studies have indicated that the onset of action of ticagrelor with respect to IPA is slower than previously suggested [77] and that there are pharmacodynamic differences compared with prasugrel [78, 79]. The use of ticagrelor suspension (crushed tablets) has the potential to increase the rate of onset of action. In the randomized MOJITO (Mashed or Just Integral Pill of Ticagrelor) study in STEMI patients, crushed ticagrelor tablets resulted in an earlier onset of IPA compared with standard integral tablets [80]. The randomized LIQUID (Oral Crushed and Dispersed Ticagrelor $180 \mathrm{mg}$ Compared to Whole Tablets of Equal Dose in STEMI Patients Undergoing Primary PCI: A Pharmacodynamic and Pharmacokinetic Comparison) 
study (ClinicalTrials.gov study ID: NCT02046486) is an extension of the MOJITO study and includes detailed pharmacokinetic and pharmacodynamic assessments.

\subsubsection{Effect of Switching Antiplatelet Agents on Ticagrelor Pharmacodynamics}

RESPOND (Response to Ticagrelor in Clopidogrel Nonresponders and Responders and Effect of Switching Therapies) was a two-way crossover study of 98 patients with stable CAD [81]. At the study start, all patients received a single $300 \mathrm{mg}$ clopidogrel dose and ADP-induced platelet aggregation was assessed prior to dosing and at $6-8 \mathrm{~h}$ postdose. If the absolute change in platelet aggregation was $\leq 10 \%$, patients were classified as non-responders. In study period 1, clopidogrel non-responders and responders were randomized $1: 1$ to receive aspirin and ticagrelor (180/ $90 \mathrm{mg}$ once daily) or clopidogrel (600/75 mg once daily) [81]. In study period 2, all non-responders and half of the current responders switched treatment (i.e. from clopidogrel to ticagrelor or from ticagrelor to clopidogrel), and the others remained on their period 1 treatment. The study reported rapid enhancement of platelet inhibition in clopidogrel responders as well as non-responders after a switch to ticagrelor. Absolute IPA increased by $26.4 \%$ in patients who switched from clopidogrel to ticagrelor treatment. In contrast, switching to clopidogrel resulted in a $24.5 \%$ reduction in absolute IPA.

Cangrelor, which binds to the same site on the $\mathrm{P} 2 \mathrm{Y}_{12}$ receptor as ticagrelor, is approved in the EU for the reduction of thrombotic cardiovascular events in adult patients with CAD undergoing percutaneous coronary intervention who have not received an oral $\mathrm{P}_{2} \mathrm{Y}_{12}$ inhibitor prior to this procedure and in whom oral therapy with $\mathrm{P} 2 \mathrm{Y}_{12}$ inhibitors is not feasible or desirable [82]. Because of its very short half-life, intravenous cangrelor leads to rapid and extensive IPA with almost full recovery of platelet activity within 60-90 min of withdrawal [83]. Potentially, in some clinical situations, patients may switch between ticagrelor or clopidogrel to cangrelor and vice versa. In a study in dogs, various switching regimens of ticagrelor, clopidogrel and cangrelor were investigated [84]. The study showed that $2 \mathrm{~h}$ after clopidogrel, IPA was reduced from 69 to $39 \%$ when clopidogrel was given after cangrelor infusion versus clopidogrel alone. When clopidogrel was dosed $3 \mathrm{~h}$ after ticagrelor, IPA was reduced from 68 to $38 \%$ at $24 \mathrm{~h}$ versus clopidogrel alone. An interaction was not seen when clopidogrel was dosed $7 \mathrm{~h}$ after ticagrelor. No pharmacodynamic interaction occurred between ticagrelor and cangrelor. The pharmacodynamic effects of switching from cangrelor to ticagrelor, and from ticagrelor to cangrelor, were assessed in patients with stable CAD [85]. Patients received a bolus plus a 2-h infusion of cangrelor and also $180 \mathrm{mg}$ of oral ticagrelor at 0.5 or $1.25 \mathrm{~h}$. Following this schedule, patients received ticagrelor ( $90 \mathrm{mg}$ twice daily) for 6 or 7 days, during which time pharmacodynamic effects were assessed on day 5 before, and during, a bolus plus 2-h infusion of cangrelor. Pharmacodynamic assessments included light transmission aggregometry, a VerifyNow $\mathrm{P}_{2} \mathrm{Y}_{12}$ assay and platelet activation. The study concluded that the pharmacodynamic effects of cangrelor were not attenuated by ticagrelor. In addition, the pharmacodynamic effects of ticagrelor were preserved when ticagrelor was given during infusion of cangrelor. These data suggest that ticagrelor can be administered before, during or after cangrelor treatment without apparent treatment interaction.

Switching from ticagrelor to prasugrel has also been evaluated in 110 patients with stable CAD [86]. An initial loading dose of ticagrelor (180 mg) was administered, followed by a 3- to 5-day run-in phase of ticagrelor $90 \mathrm{mg}$ twice daily. Patients were then randomized to continue ticagrelor or to switch to prasugrel $10 \mathrm{mg}$ once daily with or without a $60 \mathrm{mg}$ prasugrel loading dose. Switching from ticagrelor to prasugrel was associated with an increase in platelet reactivity - this effect was partially mitigated when a $60 \mathrm{mg}$ loading dose of prasugrel was administered.

\section{Ticagrelor Pharmacogenetic Profile}

Inadequate antiplatelet effects are observed in up to one third of patients receiving clopidogrel [87-89]. Reasons for this variation in response may be the presence of polymorphisms in genes such as CYP2C19 and ABCB1. In the pooled analysis of the RESPOND and ONSET/OFFSET studies [89], CYP2C19 genotype influenced the antiplatelet activity of clopidogrel, whereas the antiplatelet activity of ticagrelor was not associated with CYP2C19 genotype. Ticagrelor exhibited lower platelet reactivity (i.e. less platelet aggregation) than clopidogrel for all assays used in the study irrespective of CYP2C19 genotype. The ABCB1 genotype did not significantly influence platelet response in either the ticagrelor or clopidogrel treatment groups.

A large genetic substudy was performed as part of the PLATO trial [90]. This substudy showed that CYP2C19 and $\mathrm{ABCB} 1$ polymorphisms were independent of the lower rates of cardiovascular death, MI or stroke observed in patients treated with ticagrelor compared with clopidogrel. Rates of total major bleeding were similar between the ticagrelor and clopidogrel groups in this substudy. A genome-wide association study (GWAS) of patients from the PLATO study identified single nucleotide polymorphisms (SNPs) affecting cystatin-C levels [91]. However, the composite clinical outcome of first occurrence of MI or cardiovascular death within the first year was not 
associated with cystatin-C genotype. A further GWAS study in the PLATO trial showed that plasma levels of ticagrelor and AR-C124910XX were associated with a SNP in the solute carrier organic anion transporter family member 1B1 (SLCO1B1) gene [92]. This SNP is in linkage disequilibrium with a functional variant that leads to decreased organic anion transporting polypeptide 1B1 (OATP1B1) activity. In the same study, plasma ticagrelor levels were associated with two independent SNPs in the CYP3A4 region, and AR-C124910XX levels were associated with a SNP in the UDP-glucuronosyltransferase 2B7 (UGT2B7) gene. However, the effects on plasma ticagrelor and AR-C124910XX at each of these loci were small, and none were associated with clinical outcomes.

\section{Conclusions}

The pharmacokinetic and pharmacodynamic profiles of ticagrelor are unique. Unlike other currently available antiplatelet agents, ticagrelor does not require metabolic activation and it binds rapidly and reversibly to the $\mathrm{P}_{2} \mathrm{Y}_{12}$ receptor. Patients with ACS represent broad populations who often have comorbidities and are likely to be taking several different classes of drug. Exposure to antiplatelet agents as measured by pharmacokinetic studies may vary in different populations. Understanding the pharmacological profile of oral antiplatelet agents is important to avoid drug-drug interactions and to provide optimal dosing. This review has summarized what is currently known about the pharmacokinetic, pharmacodynamic and pharmacogenomic profiles of ticagrelor.

Studies in healthy volunteers showed that dose adjustments for ticagrelor were not required on the basis of age, gender or ethnicity. Severe renal impairment and mild hepatic impairment also do not necessitate dose adjustments. Pharmacokinetic data are not currently available in patients with moderate and severe hepatic impairment or those on renal dialysis, and use of ticagrelor in patients with severe hepatic impairment is contraindicated. Exposure to ticagrelor is higher in Japanese and Chinese populations versus Caucasians; however, these differences are not considered to be clinically relevant and dose adjustments are not required. African-American and Hispanic populations show a ticagrelor pharmacokinetic/pharmacodynamic profile similar to that of Caucasians. The clinical relevance of the increased plasma concentrations of ticagrelor observed at 0.5 and $1 \mathrm{~h}$ with use of crushed tablets has yet to be shown. Drug interaction studies show that ticagrelor should not be co-administered with strong CYP3A inhibitors or inducers, and use with statins at doses greater than $40 \mathrm{mg}$ should be avoided. Patients receiving P-gp-dependent drugs with a narrow therapeutic range, at the same time as ticagrelor, should be monitored appropriately. Current data show that proton pump inhibitors (metabolized by CYP2C enzymes) are unlikely to have any significant pharmacokinetic interaction with ticagrelor.

The non- $\mathrm{P}_{2} \mathrm{Y}_{12}$ receptor actions of ticagrelor warrant further investigation, in particular the possible beneficial effects on cardiac perfusion. Current data suggest that, if necessary, patients who are not responsive to clopidogrel can be switched directly to ticagrelor with an increase in IPA. In contrast, switching from ticagrelor to clopidogrel is associated with a reduction in IPA. Genetic variations appear to influence response to clopidogrel. However, there is currently no evidence to show that this is true for ticagrelor.

Ongoing studies will provide additional insights into the pharmacology of ticagrelor and will help support individualized $\mathrm{P} 2 \mathrm{Y}_{12}$ inhibitor treatment, in line with guideline recommendations.

Acknowledgments Renli Teng is an employee of AstraZeneca. Medical writing assistance was provided by Angela Rogers (Gardiner-Caldwell Communications, part of the KnowledgePoint 360 Group, an Ashfield company, Macclesfield, UK), and assistance with revising the paper in response to journal comments was provided by Jackie Phillipson (Zoetic Science, part of the KnowledgePoint360 Group, an Ashfield company, Macclesfield, UK); this support was funded by AstraZeneca.

Open Access This article is distributed under the terms of the Creative Commons Attribution-NonCommercial 4.0 International License (http://creativecommons.org/licenses/by-nc/4.0/), which permits any noncommercial use, distribution, and reproduction in any medium, provided you give appropriate credit to the original author(s) and the source, provide a link to the Creative Commons license, and indicate if changes were made.

\section{References}

1. Amsterdam EA, Wenger NK, Brindis RG, et al. 2014 AHA/ACC Guideline for the Management of Patients with Non-ST-Elevation Acute Coronary Syndromes: a Report of the American College of Cardiology/American Heart Association Task Force on Practice Guidelines. J Am Coll Cardiol. 2014;64:2645-87.

2. Go AS, Mozaffarian D, Roger VL, et al. Heart disease and stroke statistics-2014 update: a report from the American Heart Association. Circulation. 2014;129:e28-292.

3. Libby P, Tabas I, Fredman G, Fisher EA. Inflammation and its resolution as determinants of acute coronary syndromes. Circ Res. 2014;114:1867-79.

4. Crea F, Liuzzo G. Pathogenesis of acute coronary syndromes. J Am Coll Cardiol. 2013;61:1-11.

5. O'Gara PT, Kushner FG, Ascheim DD, et al. 2013 ACCF/AHA guideline for the management of ST-elevation myocardial infarction: a report of the American College of Cardiology Foundation/American Heart Association Task Force on Practice Guidelines. J Am Coll Cardiol. 2013;61:e78-140.

6. Hamm CW, Bassand JP, Agewall S, et al. ESC guidelines for the management of acute coronary syndromes in patients presenting 
without persistent ST-segment elevation: the Task Force for the Management of Acute Coronary Syndromes (ACS) in Patients Presenting Without Persistent ST-Segment Elevation of the European Society of Cardiology (ESC). Eur Heart J. 2011;32:2999-3054.

7. Steg PG, James SK, Atar D, et al. ESC guidelines for the management of acute myocardial infarction in patients presenting with ST-segment elevation: the Task Force for the Management of ST-Segment Elevation Myocardial Infarction of the European Society of Cardiology (ESC). Eur Heart J. 2012;33:2569-619.

8. Yusuf S, Zhao F, Mehta SR, Chrolavicius S, Tognoni G, Fox KK, Clopidogrel in Unstable Angina to Prevent Recurrent Events Trial Investigators. Effects of clopidogrel in addition to aspirin in patients with acute coronary syndromes without ST-segment elevation. N Engl J Med. 2001;345:494-502.

9. Hulot JS, Bura A, Villard E, et al. Cytochrome P450 2C19 lossof-function polymorphism is a major determinant of clopidogrel responsiveness in healthy subjects. Blood. 2006;108:2244-7.

10. Sorich MJ, Rowlan A, McKinnon RA, Wiese MD. CYP2C19 genotype has a greater effect on adverse cardiovascular outcomes following PCI and in Asian populations treated with clopidogrel: a meta-analysis. Circ Cardiovasc Genet. 2014;7:895-902.

11. Tresukosol D, Suktitipat B, Hunnangkul S, et al. Effects of cytochrome P450 2C19 and paraoxonase 1 polymorphisms on antiplatelet response to clopidogrel therapy in patients with coronary artery disease. PLos One. 2014;9:e110188.

12. Jakubowski JA, Matsushima N, Asai F, et al. A multiple dose study of prasugrel (CS-747), a novel thienopyridine P2Y12 inhibitor, compared with clopidogrel in healthy humans. Br J Clin Pharmacol. 2007;63:421-30.

13. Wiviott SD, Braunwald E, McCabe $\mathrm{CH}$, et al. Prasugrel versus clopidogrel in patients with acute coronary syndromes. N Engl J Med. 2007;357:2001-15.

14. van Giezen JJ, Nilsson L, Berntsson P, et al. Ticagrelor binds to human P2Y(12) independently from ADP but antagonizes ADPinduced receptor signaling and platelet aggregation. J Thromb Haemost. 2009; 7:1556-65.

15. Wallentin L, Becker RC, Budaj A, et al. Ticagrelor versus clopidogrel in patients with acute coronary syndromes. N Engl J Med. 2009;361:1045-57.

16. Bonaca MP, Bhatt DL, Cohen M, et al. Long-term use of ticagrelor in patients with prior myocardial infarction. N Engl J Med. 2015;372:1791-800.

17. Teng R. Pharmacokinetic, pharmacodynamic and pharmacogenetic profile of the oral antiplatelet agent ticagrelor. Clin Pharmacokinet. 2012;51:305-18.

18. Teng R, Maya J. Absolute bioavailability and regional absorption of ticagrelor in healthy volunteers. J Drug Assess. 2014;3:43-50.

19. Teng R, Butler K. Pharmacokinetics, pharmacodynamics, tolerability and safety of single ascending doses of ticagrelor, a reversibly binding oral $\mathrm{P} 2 \mathrm{Y}_{12}$ receptor antagonist, in healthy subjects. Eur J Clin Pharmacol. 2010;66:487-96.

20. Teng R, Oliver S, Hayes MA, Butler K. Absorption, distribution, metabolism and excretion of ticagrelor in healthy subjects. Drug Metab Dispos. 2010;38:1514-21.

21. Teng R, Carlson G, Hsia J. An open-label, randomized bioavailability study with alternative methods of administration of crushed ticagrelor tablets in healthy volunteers. Int J Clin Pharmacol Ther. 2015;53:182-9.

22. Storey RF, Husted S, Harrington RA, et al. Inhibition of platelet aggregation by AZD6140, a reversible oral P2Y12 receptor antagonist, compared with clopidogrel in patients with acute coronary syndromes. J Am Coll Cardiol. 2007;50:1852-6.

23. Butler K, Teng R. Pharmacokinetics, pharmacodynamics, safety and tolerability of multiple ascending doses of ticagrelor in healthy volunteers. Br J Clin Pharmacol. 2010;70:65-77.
24. Husted S, Emanuelsson H, Heptinstall S, et al. Pharmacodynamics, pharmacokinetics, and safety of the oral reversible P2Y12 antagonist AZD6140 with aspirin in patients with atherosclerosis: a double-blind comparison to clopidogrel with aspirin. Eur Heart J. 2006;27:1038-47.

25. Husted SE, Storey RF, Bliden K, et al. Pharmacokinetics and pharmacodynamics of ticagrelor in patients with stable coronary artery disease: results from the ONSET-OFFSET and RESPOND studies. Clin Pharmacokinet. 2012;51:397-409.

26. Teng R, Mitchell PD, Butler K. Lack of significant food effect on the pharmacokinetics of ticagrelor in healthy volunteers. J Clin Pharm Ther. 2012;37:464-8.

27. Li Y, Landqvist C, Grimm SW. Disposition and metabolism of ticagrelor, a novel $\mathrm{P} 2 \mathrm{Y}_{12}$ receptor antagonist, in mice, rats, and marmosets. Drug Metab Dispos. 2011;39:1555-67.

28. Zhou D, Andersson TB, Grimm SW. In vitro evaluation of potential drug-drug interactions with ticagrelor: cytochrome $\mathrm{P} 450$ reaction phenotyping, inhibition, induction and differential kinetics. Drug Metab Dispos. 2011;39:703-10.

29. AstraZeneca LP. Brilinta (ticagrelor) tablets. Approved prescribing information. Updated Mar 29, 2013. Available at: http:// www1.astrazeneca-us.com/pi/brilinta.pdf. Accessed 24 Mar 2015.

30. Sanofi, Bristol-Myers Squibb. Plavix (clopidogrel bisulfate) tablets. Approved prescribing information. Updated Dec 2013. Available at: http://packageinserts.bms.com/pi/pi_plavix.pdf. Accessed 27 Mar 2015.

31. Eli Lilly and Company. Effient (prasugrel) tablets. Approved prescribing information. Updated Nov 2013. Available at: http:// pi.lilly.com/us/effient.pdf. Accessed 27 Mar 2015.

32. Teng R, Mitchell P, Butler K. Effect of age and gender on the pharmacokinetics and pharmacodynamics of a single ticagrelor dose in healthy subjects. Eur J Clin Pharmacol. 2012;68:1175-82.

33. Butler K, Teng R. Pharmacokinetics, pharmacodynamics, and safety of ticagrelor in volunteers with severe renal impairment. J Clin Pharmacol. 2012;52:1388-98.

34. Butler K, Teng R. Pharmacokinetics, pharmacodynamics, and safety of ticagrelor in volunteers with mild hepatic impairment. J Clin Pharmacol. 2011;51:978-87.

35. Nylander S, Femia E, Scavone $M$, et al. Ticagrelor inhibits human platelet aggregation via adenosine in addition to $\mathrm{P} 2 \mathrm{Y}_{12}$ antagonism. J Thromb Haemost. 2013;11:1867-76.

36. Belchikov YG, Koenig SJ, Dipasquale EM. Potential role of endogenous adenosine in ticagrelor-induced dyspnea. Pharmacotherapy. 2013;33:882-7.

37. Burki NK, Dale WJ, Lee LY. Intravenous adenosine and dyspnea in humans. J Appl Physiol. 1985;2005(98):180-5.

38. Burki NK, Alam M, Lee LY. The pulmonary effects of intravenous adenosine in asthmatic subjects. Respir Res. 2006;7:139.

39. Butler K, Maya J, Teng R. Effect of ticagrelor on pulmonary function in healthy elderly volunteers and asthma or chronic obstructive pulmonary disease patients. Curr Med Res Opin. 2013;29:569-77.

40. Waksman R, Maya J, Angiolillo D, et al. Ticagrelor versus clopidogrel in African American patients with coronary artery disease and diabetes mellitus. $\mathrm{J}$ Am Coll Cardiol. 2014;63(12_S):A211.

41. Li H, Butler K, Yang L, Yang Z, Teng R. Pharmacokinetics and tolerability of single and multiple doses of ticagrelor in healthy Chinese subjects: an open-label, sequential, two-cohort, singlecentre study. Clin Drug Invest. 2012;32:87-97.

42. Teng R, Butler K. Pharmacokinetics, pharmacodynamics and tolerability of single and multiple doses of ticagrelor in Japanese and Caucasian volunteers. Int $\mathrm{J}$ Clin Pharmacol Ther. 2014;52:478-91. 
43. Hiasa Y, Teng R, Emanuelsson H. Pharmacodynamics, pharmacokinetics and safety of ticagrelor in Asian patients with stable coronary artery disease. Cardiovasc Interv Ther. 2014;29:324-33.

44. Price MJ, Clavijo L, Angiolillo D, et al. A randomized trial of the pharmacodynamic and pharmacokinetic effects of ticagrelor compared with clopidogrel in Hispanic patients with stable coronary artery disease. J Thromb Thrombolysis. 2014;39:8-14.

45. Waksman R, Maya J, Angiolillo D, et al. Ticagrelor versus clopidogrel in African American patients with stable coronary artery disease: a randomized, open-label, multiple-dose, crossover study. J Am Coll Cardiol Intv. 2014;7(2_S):S6 Abstract CRT-99.

46. Teng R, Butler K. The effect of ticagrelor on the metabolism of midazolam in healthy volunteers. Clin Ther. 2013;35:1025-37.

47. Teng R, Mitchell P, Butler K. Pharmacokinetic interaction studies of co-administration of ticagrelor and atorvastatin or simvastatin in healthy volunteers. Eur J Clin Pharmacol. 2013;69:477-87.

48. Butler K, Teng R. Effect of ticagrelor on the pharmacokinetics of ethinyl oestradiol and levonorgestrel in healthy volunteers. Curr Med Res Opin. 2011;27:1585-93.

49. Teng R, Mitchell P, Butler K. Evaluation of the pharmacokinetic interaction between ticagrelor and tolbutamide, a cytochrome $\mathrm{P} 45$ 2C9 substrate, in healthy volunteers. Int J Clin Pharmacol Ther. 2013;51:305-12.

50. Agewall S, Cattaneo M, Collet JP, et al. Expert position paper on the use of proton pump inhibitors in patients with cardiovascular disease and antithrombotic therapy. Eur Heart J. 2013;34:1708-13.

51. Teng R, Kujacic M, Hsia J. Evaluation of the pharmacokinetic interaction between ticagrelor and venlafaxine, a cytochrome P-450 2D6 substrate, in healthy subjects. Clin Ther. 2014;36:1217-25.

52. Teng R, Butler K. A pharmacokinetic interaction study of ticagrelor and digoxin in healthy volunteers. Eur J Clin Pharmacol. 2013;69:1801-8.

53. Teng R, Mitchell P, Butler K. Effect of rifampicin on the pharmacokinetics and pharmacodynamics of ticagrelor in healthy subjects. Eur J Clin Pharmacol. 2013;69:877-83.

54. Holmberg MT, Tornio A, Joutsi-Korhonen L, et al. Grapefruit juice markedly increases the plasma concentrations and antiplatelet effects of ticagrelor in healthy subjects. Br J Clin Pharmacol. 2013;75:1488-96.

55. Teng R, Butler K. Effect of the CYP3A inhibitors, diltiazem and ketoconazole, on ticagrelor pharmacokinetics in healthy volunteers. J Drug Assess. 2013;2:30-9.

56. Teng R, Kujacic M, Hsia J. Effect of the cyclosporine on ticagrelor pharmacokinetics in healthy volunteers. Clin Drug Investig. 2014;34:529-36.

57. Teng R, Butler K. Lack of clinically significant pharmacological interactions between ticagrelor and enoxaparin or unfractionated heparin in healthy subjects. J Clin Pharm Ther. 2012;37:704-11.

58. Mahaffey KW, Wojdyla DM, Carroll K, et al. Ticagrelor compared with clopidogrel by geographic region in the platelet inhibition and patient outcomes (PLATO) trial. Circulation. 2011;124:544-54.

59. Husted S, van Giezen JJ. Ticagrelor: the first reversibly binding oral P2Y12 receptor antagonist. Cardiovasc Ther. 2009;27:259-74.

60. Patil SB, Norman KE, Robins SJ, et al. Inhibition of thrombosis by AZD6140 via selective blockade of the $\mathrm{P}_{2} \mathrm{Y}_{12}$ receptor in a murine laser-injury model. J Thromb Haemost. 2007;5(Suppl 1):P-W-632.

61. Guthikonda S, Alviar CL, Vaduganathan M, et al. Role of reticulated platelets and platelet size heterogeneity on platelet activity after dual antiplatelet therapy with aspirin and clopidogrel in patients with stable coronary artery disease. J Am Coll Cardiol. 2008;52:743-9.
62. Kuijpers MJE, Megens RTA, Nikookhesal E, et al. Role of newly formed platelets in thrombus formation after clopidogrel treatment: comparison to the reversible P2Y12 antagonist ticagrelor. Thromb Haemost. 2011;106:1179-88.

63. Teng R, Mitchell P, Butler K. The effect of desmopressin on bleeding time and platelet aggregation in healthy volunteers administered ticagrelor. J Clin Pharm Ther. 2014;39:186-91.

64. Buchanan A, Newton P, Pehrsson S, et al. Structural and functional characterisation of a specific antidote for ticagrelor. Blood. 2015;125:3484-90.

65. Vilahur G, Choi BG, Zafar MU, et al. Normalization of platelet reactivity in clopidogrel-treated subjects. J Thromb Haemost. 2007;5:82-90.

66. Prüller F, Drexler C, Archan S, Macher S, Raggam RB, Mahla E. Low platelet reactivity is recovered by transfusion of stored platelets: a healthy volunteer in vivo study. J Thromb Haemost. 2011;9:1670-3.

67. Armstrong D, Summers C, Ewart L, Nylander S, Sidaway JE, Van Giezen H. Characterisation of the adenosine pharmacology of ticagrelor reveals therapeutically relevant inhibition of equilibrative nucleoside transporter-1. J Cardiovasc Pharmacol Ther. 2014;19:209-19.

68. Wittfeldt A, Emanuelsson H, Brandrup-Wognsen G, et al. Ticagrelor enhances adenosine-induced coronary vasodilatory responses in humans. J Am Coll Cardiol. 2013;61:723-7.

69. Cattaneo M, Schulz R, Nylander S. Adenosine-mediated effects of ticagrelor: evidence and potential clinical relevance. J Am Coll Cardiol. 2014;63:2503-9.

70. Nanhwan MK, Ling S, Kodakandla M, Nylander S, Ye Y, Birnbaum Y. Chronic treatment with ticagrelor limits myocardial infarct size: an adenosine and cyclooxygenase-2-dependent effect. Arterioscler Thromb Vasc Biol. 2014;34:2078-85.

71. Reiner MF, Stivala S, Akhmedov A, et al. Cell-specific off-target effects of ticagrelor but not clopidogrel-active metabolite in endothelial dysfunction. Eur Heart J. 2014;35(Suppl 1):199.

72. Donahoe SM, Stewart GC, McCabe CH, et al. Diabetes and mortality following acute coronary syndromes. JAMA. 2007;298:765-75.

73. Held C, Asenblad N, Bassand JP, et al. Ticagrelor versus clopidogrel in patients with acute coronary syndromes undergoing coronary artery bypass surgery: results from the PLATO (Platelet Inhibition and Patient Outcomes) trial. J Am Coll Cardiol. 2011;57:672-84.

74. Storey RF, Angiolillo DJ, Patil SB, et al. Inhibitory effects of ticagrelor compared with clopidogrel on platelet function in patients with acute coronary syndromes. J Am Coll Cardiol. 2010;561:1456-62.

75. Cannon CP, Husted S, Harrington RA, et al. Safety, tolerability, and initial efficacy of AZD6140, the first reversible oral adenosine diphosphate receptor antagonist, compared with clopidogrel, in patients with non-ST-segment elevation acute coronary syndrome: primary results of the DISPERSE-2 trial. J Am Coll Cardiol. 2007;50:1844-51.

76. Parodi G, Valenti R, Bellandi B, et al. Comparison of prasugrel and ticagrelor loading doses in ST-segment elevation myocardial infarction patients: RAPID (Rapid Activity of Platelet Inhibitor Drugs) primary PCI study. J Am Coll Cardiol. 2013;61:1601-6.

77. Alexopoulos D, Gkizas V, Patsilinakos S, et al. Double versus standard loading dose of ticagrelor: onset of antiplatelet action in patients with STEMI undergoing primary PCI. J Am Coll Cardiol. 2013;62:940-1.

78. Alexopoulos D, Xanthopoulou I, Gkizas V, et al. Randomized assessment of ticagrelor versus prasugrel antiplatelet effects in patients with ST-segment-elevation myocardial infarction. Circ Cardiovasc Interv. 2012;5:797-804.

79. Sugidachi A, Ohno K, Ogawa T, Jakubowski J, Hashimoto M, Tomizawa A. A comparison of the pharmacological profiles of 
prasugrel and ticagrelor assessed by platelet aggregation, thrombus formation and haemostasis in rats. $\mathrm{Br} \mathrm{J}$ Pharmacol. 2013;169:82-9.

80. Parodi G, Xanthopoulou I, Bellandi B, et al. Ticagrelor crushed tablets administration in STEMI patients: the MOJITO study. J Am Coll Cardiol. 2015;65:511-2.

81. Gurbel PA, Bliden KP, Butler K, et al. Response to ticagrelor in clopidogrel non-responders and responders and effect of switching therapies: the RESPOND study. Circulation. 2010;121:1188-99.

82. The Medicines Company UK Ltd. Kengrexal (cangrelor) powder. Patient information leaflet. Updated Apr 8, 2015. Available at: https://www.medicines.org.uk/emc/medicine/30245. Accessed 13 Apr 2015.

83. Akers WS, Oh JJ, Oestreich JH, Ferraris S, Wethington M, Steinhubl SR. Pharmacokinetics and pharmacodynamics of a bolus and infusion of cangrelor: a direct, parenteral P2Y12 receptor antagonist. J Clin Pharmacol. 2010;50:27-35.

84. Ravnefjord A, Weilitz J, Emanuelsson BM, van Giezen JJ. Evaluation of ticagrelor pharmacodynamic interactions with reversibly-binding or non-reversibly-binding P2Y12 antagonists in an ex-vivo canine model. Thromb Res. 2012;130:622-8.

85. Schneider DJ, Agarwal Z, Seecheran N, Keating FK, Gogo P. Pharmacodynamic effects during the transition between cangrelor and ticagrelor. JACC Cardiovasc Interv. 2014;7:435-42.

86. Angiolillo DJ, Curzen N, Gurbel P, et al. Pharmacodynamic evaluation of switching from ticagrelor to prasugrel in patients with stable coronary artery disease: results of the SWAP-2 study (Switching Anti Platelet-2). J Am Coll Cardiol. 2014;63:1500-9.

87. Matetzky S, Shenkman B, Guetta V, et al. Clopidogrel resistance is associated with increased risk of recurrent atherothrombotic events in patients with acute myocardial infarction. Circulation. 2004;109:3171-5.

88. Müller I, Besta F, Schulz C, Massberg S, Schönig A, Gawaz M. Prevalence of clopidogrel non-responders among patients with stable angina pectoris scheduled for elective coronary stent placement. Thromb Haemost. 2003;89:783-7.

89. Tantry US, Bliden KP, Wei C, et al. First analysis of the relation between CYP2C19 genotype and pharmacodynamics in patients treated with ticagrelor versus clopidogrel: the ONSET/OFFSET and RESPOND genotype studies. Circ Cardiovasc Genet. 2010;3:556-66.

90. Wallentin L, James S, Storey RF, et al. Effect of CYP2C19 and $\mathrm{ABCB} 1$ single nucleotide polymorphisms on outcomes of treatment with ticagrelor versus clopidogrel for acute coronary syndromes: a genetic substudy of the PLATO trial. Lancet. 2010;376:1320-8.

91. Akerblom A, Eriksson N, Wallentin L, et al. Polymorphism of the cystatin $\mathrm{C}$ gene in patients with acute coronary syndromes: results from the Platelet Inhibition and Patient Outcomes Study. Am Heart J. 2014;168(96-102):e2.

92. Varenhorst $\mathrm{CMH}$, Eriksson N, Johansson $\AA$, et al. Ticagrelor plasma levels but not clinical outcomes are associated with transporter and metabolism enzyme genetic polymorphisms. J Am Coll Cardiol. 2014;63(12_S):A25. 